\title{
Asymmetric Anionic Polymerization of 1-Phenyldibenzosuberyl and 1-(2-Pyridyl)dibenzosuberyl Methacrylates and Chiral Recognition Ability of the Obtained Polymers ${ }^{1}$
}

\author{
Tamaki Nakano, Akihiro Matsuda, Masatoshi Mori, and Yoshio OKamoto
}

\author{
Department of Applied Chemistry, School of Engineering, Nagoya University, \\ Furo-cho, Chikusa-ku, Nagoya 464-01, Japan
}

(Received September 11, 1995)

\begin{abstract}
Asymmetric anionic polymerization of 1-phenyldibenzosuberyl methacrylate [5-phenyldibenzosuberan-5yl methacrylate, 5-phenyl-10,11-dihydrodibenzo[a,d]cyclohepten-5-yl methacrylate] (1), and 1-(2-pyridyl)dibenzosuberyl methacrylate [5-(2-pyridyl)dibenzosuberan-5-yl methacrylate, 5-(2-pyridyl)-10,11-dihydrodibenzo[ $a, d]$ cyclohepten-5-yl methacrylate] (2) was carried out using complexes of $N, N^{\prime}$-diphenylethylenediamine monolithium amide with (-)-sparteine (Sp), (+)-1-(2-pyrrolidinylmethyl)pyrrolidine (PMP), and (+)-2,3-dimethoxy-1,4-bis(dimethylamino)butane (DDB) in toluene at $-78^{\circ} \mathrm{C}$. The polymers of 1 quantitatively obtained with the three complexes were highly isotactic and showed high optical activity $\left([\alpha]_{365}+1670-1780^{\circ},[\alpha]_{\mathrm{D}}+420-480^{\circ}\right)$ and intense circular dichroism absorptions based on one-handed helical conformation of main chain. In contrast, 2 gave one-handed helical polymers only by the polymerization with the Sp and PMP complexes. The polymerization of $\mathbf{2}$ with the DDB complex was sluggish. Monomers $\mathbf{1}$ and $\mathbf{2}$ showed higher resistance against methanolysis compared with triphenylmethyl methacrylate and diphenyl-2-pyridylmethyl methacrylate, respectively. The obtained optically active polymers resolved several racemic compounds.
\end{abstract}

KEY WORDS Helix / Asymmetric Anionic Polymerization / 1-Phenyldibenzosuberyl Methacrylate / 1-(2-Pyridyl)dibenzosuberyl Methacrylate / Triphenylmethyl Methacrylate / Diphenyl-2-pyridylmethyl Methacrylate / (+)-1-(2-Pyrrolidinylmethyl)pyrrolidine / (+)-2,3-Dimethoxy-1,4-bis(dimethylamino)butane / (-)-Sparteine/

Optically active polymers having helical conformation are obtained by asymmetric polymerization of achiral monomers including methacrylates, isocyanates, isocyanides, and chloral. ${ }^{2}$ The importance of the helical polymers lies in application for chiral recognition of racemic compounds in addition to unique structural characteristics. Purely one-handed helical poly(triphenylmethyl methacrylate) [poly(TrMA)] is the first vinyl polymer of its kind. ${ }^{3-6}$ Poly(TrMA) has an almost perfectly isotactic configuration and its helical conformation is maintained by steric repulsion between the bulky side groups. One-handed helical polymers have been obtained by anionic polymerization with the complexes of organolithiums and chiral ligands. Poly(TrMA) can resolve many classes of racemates when used as chiral stationary phase for high performance liquid chromatography (HPLC). ${ }^{7}$

However, the poly(TrMA) has a shortcoming that the ester linkage is readily solvolyzed by methanol which is often used as an HPLC eluent. In order to overcome this drawback, we synthesized several TrMA-analogues including those having electron-withdrawing substituent on the phenyl groups ${ }^{8}$ or a pyridyl group ${ }^{9-11}$ in place of a phenyl group. In the present work, we synthesized and polymerized 1-phenyldibenzosuberyl methacrylate (PDBSMA) and 1-(2-pyridyl)dibenzosuberyl methacrylate (2PyDBSMA) having a dibenzosuberyl moiety in the ester group in order to obtain novel, solvolysis-resistant optically active polymethacrylates. Solvolysis of triaryl esters is considered to involve a triaryl cation as an intermediate. The triaryl cation can be stabilized by delocalization of the cation by the planar resonance structures. We assumed that PDBSMA and 2PyDBSMA are more resistant against methanolysis than TrMA and diphenyl-2-pyridylmethyl methacrylate (D2PyMA), their parent monomers, respectively, since the planar structures are difficult to attain for a 1-phenyldibenzosuberyl and a 1-(2-pyridyl)dibenzosuberyl cations due to the presence of an ethylene group tying two phenyl groups.

The present article describes the anionic polymerization of PDBSMA and 2PyDBSMA with the complexes of $N, N^{\prime}$-diphenylethylenediamine monolithium amide (DPEDA-Li) with (+)-1-(2-pyrrolidinylmethyl)pyrrolidine (PMP), (+)-2,3-dimethoxy-1,4-bis(dimethylamino)-
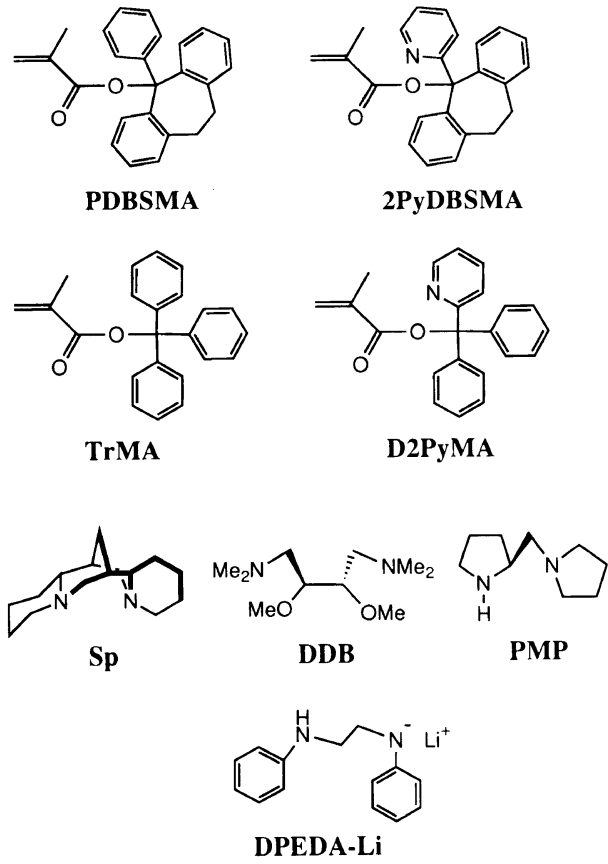
butane (DDB), and (-)-sparteine ( $\mathrm{Sp}$ ) and chiral recognition by the obtained polymers. We briefly reported the preliminary results of the anionic polymerization of PDBSMA $^{12}$ and the stereospecific radical polymerization of the same monomer. ${ }^{13}$

\section{EXPERIMENTAL}

\section{Materials}

Synthesis and purification of PDBSMA have been described in our recent publication. ${ }^{12,14} 2$-Bromopyridine was dried on $\mathrm{CaH}_{2}$ and distilled immediately before use. Dibenzosuberone was used as obtained (Aldrich). Ether and tetrahydrofuran (THF) were distilled over $\mathrm{Na}$ wire. Purification of the other materials including those for anionic polymerization has been shown in the literature. ${ }^{6}$

\section{Synthesis of $2 P y D B S M A$}

1-(2-Pyridyl)dibenzosuberol ${ }^{15}$ was synthesized by a literature method ${ }^{16}$ with modification. The reactions were performed under $\mathrm{N}_{2}$ atmosphere. In a 2-L flask filled with a dropping funnel, 2-bromopyridine (75 g, $0.475 \mathrm{mmol}$ ) was dissolved in $325 \mathrm{ml}$ of dry ether and the solution was cooled at $-78^{\circ} \mathrm{C}$. $n$-BuLi in a hexane solution $(1.56 \mathrm{M})$ and then dibenzosuberone $(95.1 \mathrm{~g}$, $0.457 \mathrm{~mol})$ in a dry ether $(190 \mathrm{ml})$ solution were added dropewise to the solution. After stirring for an hour, the mixture was allowed to stand at $-35^{\circ} \mathrm{C}$ for $4 \mathrm{~h}$ and decomposed by adding aq. $\mathrm{NH}_{4} \mathrm{Cl}$. A white crystal precipitated in the aqueous layer was identified as the product; this was collected by filtration and dried under vacuum at $60^{\circ} \mathrm{C}$. Yield $104.1 \mathrm{~g}(79.3 \%)$. The crude crystal was purified by recrystallization from a mixture of $\mathrm{CHCl}_{3}$ and ether to yield a pure crystal of the alcohol. Yield $88.9 \mathrm{~g}(67.7 \%)$. mp $205-206^{\circ} \mathrm{C}$ (lit. $^{16} 201-$ $\left.204^{\circ} \mathrm{C}\right) .{ }^{1} \mathrm{H}$ NMR $\left(500 \mathrm{MHz}, \mathrm{CDCl}_{3}, 25^{\circ} \mathrm{C}\right) \delta 7.05-8.53$ $(\mathrm{m}, 12 \mathrm{H}$, aromatic $\mathrm{H}), 3.78(\mathrm{~s}, 1 \mathrm{H}, \mathrm{OH}), 2.82-2.93$ (m, 4H, $-\mathrm{CH}_{2} \mathrm{CH}_{2}-$ ). Anal. Calcd for $\mathrm{C}_{20} \mathrm{H}_{17} \mathrm{ON}: \mathrm{C}$, $83.59 \%$; H, 5.96\%; N, 4.87\%. Found: C, $83.59 \%$; $5.99 \% ; \mathrm{N}, 4.93 \%$.

In a 2-L flask equipped with a dropping funnel was placed $\mathrm{NaH}$ (suspension in paraffin, assay 60\%) (29.2 g, $0.730 \mathrm{~mol})$. THF $(200 \mathrm{ml})$ was introduced with a syringe to remove paraffin from $\mathrm{NaH}$ and the supernatant THF wash was removed after stirring. THF $(40 \mathrm{ml})$ was further added to the washed $\mathrm{NaH}$ and 1-(2-pyridyl)dibenzosuberol $(41.2 \mathrm{~g}, 0.143 \mathrm{~mol})$ dissolved in $640 \mathrm{ml}$ of dry THF was added dropwise in a 2.5 -h period with stirring at room temperature. After completion of $\mathrm{H}_{2}$ generation, methacryloyl chloride $(20.0 \mathrm{ml}, 0.205 \mathrm{~mol})$ dissolved in $40 \mathrm{ml}$ of dry THF was added dropwise to the mixture cooled at $0^{\circ} \mathrm{C}$. After stirring for $2 \mathrm{~h}$ at $0^{\circ} \mathrm{C}$ and for additional $1 \mathrm{~h}$ at $70^{\circ} \mathrm{C}$, the reaction mixture was decomposed by adding water. The product was extracted with a mixture of ether and benzene. The organic layer was dried on $\mathrm{MgSO}_{4}$ and removal of solvent gave a yellow crystal. Yield $47.6 \mathrm{~g}(93.6 \%)$. The crude crystal was first purified by silica gel column chromatography using a mixture of benzene and ether (20/1) as the eluent and then recrystallized twice from a benzene-ether mixture $(1 / 1)$ and once from a benzene-hexane mixture $(1 / 1)$. Yield $18.5 \mathrm{~g}(36.3 \%)$. mp $168-169^{\circ} \mathrm{C}$. ${ }^{1} \mathrm{H}$ NMR $\left(500 \mathrm{MHz} \mathrm{CDCl}_{3}, 25^{\circ} \mathrm{C}\right) \delta 7.05-8.39(\mathrm{~m}, 12 \mathrm{H}$, aromatic $\mathrm{H}), 5.65-6.30(\mathrm{~m}, 2 \mathrm{H}$, vinyl $\mathrm{H}), 3.21-3.46(\mathrm{~m}$, $\left.4 \mathrm{H},-\mathrm{CH}_{2} \mathrm{CH}_{2}-\right), 2.00\left(\mathrm{~s}, 3 \mathrm{H}, \alpha-\mathrm{CH}_{3}\right)$. IR (KBr) 1638 $\mathrm{cm}^{-1} \quad(\mathrm{C}=\mathrm{C}), 1729 \mathrm{~cm}^{-1} \quad(\mathrm{C}=\mathrm{O})$. Anal. Calcd for $\mathrm{C}_{24} \mathrm{H}_{21} \mathrm{O}_{2} \mathrm{~N}$ : C, $81.10 \%$; H, 5.96\%; N, 3.94\%. Found: C, $81.09 \%$; H, 5.97\%; N, 3.91\%.

\section{Anionic Polymerization and Analysis of the Obtained Polymer}

The method of polymerization is the same as that for TrMA $^{6}$ except that DPEDA-Li was used in the present work rather than 9-fluorenyllithium. See Figures 2 and 6 and Tables II and III for more detail of the conditions. Tacticity of the polymers was determined from ${ }^{1} \mathrm{H}$ NMR spectra $\left(\mathrm{CDCl}_{3}, 60^{\circ} \mathrm{C}\right)$ of poly(methyl methacrylate) [poly(MMA)] derived from the original polymers. The degree of polymerization (DP) and molecular weight distribution were determined by gel permeation chromatography (GPC) of the poly(MMA) or the original polymer (see footnotes e and $f$ of Table III) using a polystyrene calibration curve.

The polymers containing oligomeric products $(0.2 \mathrm{~g})$ were dissolved in THF $(4 \mathrm{ml})$. This solution was added dropewise to $50 \mathrm{ml}$ of a mixture of benzene and hexane $(1 / 1)$ with stirring and the precipitated polymer was collected by a centrifuge.

\section{Preparation of a Chiral HPLC Column of Poly- (2PyDBSMA)}

The optically active poly(2PyDBSMA) (run 3 in Table III) $(0.75 \mathrm{~g})$ dissolved in $5 \mathrm{ml}$ of $\mathrm{CHCl}_{3}$ was added to silica gel (Daisogel, particle side $7 \mu \mathrm{m}$, pore size $1000 \AA$ ) silanized with 3-aminopropyltriethoxysilane and the gel was dried under reduced pressure. The chiral packing material thus obtained was packed in a stainless steel column $[25 \times 0.46$ (i.d.) $\mathrm{cm}]$ by a slurry method. The theoretical plate number of the column for acetone was 3700 and the dead volume measured for $\mathrm{H}_{2} \mathrm{O}$ was $3.3 \mathrm{ml}$. HPLC was performed using $\mathrm{MeOH}$ as an eluent at a flow rate of $0.5 \mathrm{ml} / \mathrm{min}$ at an ambient temperature (ca. $\left.25^{\circ} \mathrm{C}\right)$ with UV $(254 \mathrm{~nm})$ and polarimetric $\left(\alpha_{\mathrm{Hg}}\right)$ detections.

\section{Measurements}

${ }^{1} \mathrm{H}$ NMR spectra were taken on a Varian VXR-500 spectrometer $(500 \mathrm{MHz})$. Optical rotation was measured with a JASCO DIP-181 polarimeter. Circular dichroism (CD) spectra were taken using a JASCO J-720L spectrometer. GPC of poly(PDBSMA) was performed with a JASCO PU-986 chromatographic pump equipped with a $875 \mathrm{UV}$ detector and a DIP-181C polarimetric $\left(\alpha_{\mathrm{Hg}}\right)$ detector using a TOSOH TSK-G4000H8 and a Shodex K802.5 GPC columns connected in series (eluent, $\mathrm{CHCl}_{3}$; flow rate, $1.0 \mathrm{ml} \mathrm{min}^{-1}$ ). A JASCO DIP-182 polarimetric $\left(\alpha_{780 \mathrm{~nm}}\right)$ detector was used in place of DIP-181C for GPC analysis of poly(2PyDBSMA). GPC of poly(MMA)s was performed at $30^{\circ} \mathrm{C}$ with a TOSOH HLC802A chromatograph equipped with a TSK$\mathrm{G} 3000 \mathrm{H} 8$ and a $\mathrm{G} 5000 \mathrm{H} 6$ columns connected in series (eluent, $\mathrm{CHCl}_{3}$; flow rate, $1.2 \mathrm{ml} \mathrm{min}^{-1}$ ). $\mathrm{HPLC}$ resolution was performed using a JASCO 880-PU chromatographic pump, a 875-UV UV detector, and a DIP-182 polarimetric detector. 


\section{RESULTS AND DISCUSSION}

\section{Methanolysis of PDBSMA and 2PyDBSMA}

In order to evaluate how resistant the two monomers are against solvolysis, the rate of methanolysis was determined. The methanolysis reaction was carried out in a mixture of $\mathrm{CD}_{3} \mathrm{OD}$ and $\mathrm{CDCl}_{3}$ at $35^{\circ} \mathrm{C}$ using an NMR sample tube as a reaction vessel and was directly monitored by ${ }^{1} \mathrm{H}$ NMR spectroscopy. First order plots are shown in Figure $1 .{ }^{17}$ The rate constant of methanolysis $(k)$ was obtained as the slope of the graph and the half-life period was calculated from $k$ (Table I). The half-life period for PDBSMA was $c a$. six times longer than that for TrMA ${ }^{8}$ and that for 2PyDBSMA was 1.6 times longer than that for D2PyMA, ${ }^{18}$ proving the validity of our monomer design. These results demon-
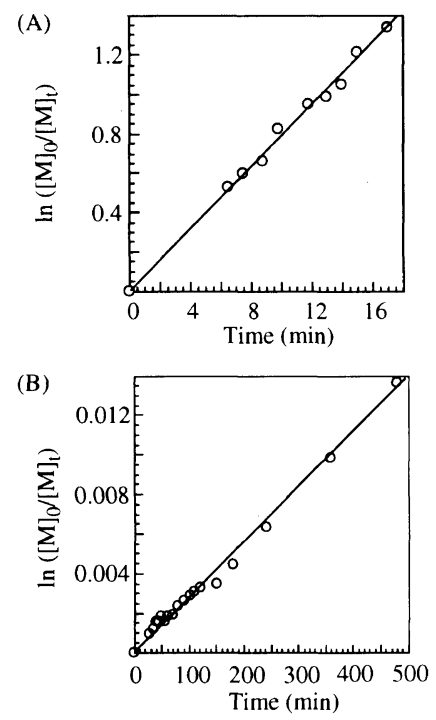

Figure 1. Methanolysis of PDBSMA (A) and 2PyDBSMA (B) in $\mathrm{CDCl}_{3}-\mathrm{CD}_{3} \mathrm{OD}(1: 1)$ at $35^{\circ} \mathrm{C}$.

Table I. Methanolysis of bulky methacrylates in $\mathrm{CDCl}_{3}-\mathrm{CD}_{3} \mathrm{OD}(1 / 1)$ at $35^{\circ} \mathrm{C}^{\mathrm{a}}$

\begin{tabular}{llc}
\hline & & Half-life period \\
\cline { 3 - 3 } Methacyrlate & $k^{\mathrm{b}} / \mathrm{h}^{-1}$ & $\min$ \\
\hline PDBSMA & & 89.0 \\
TrMA $^{\mathrm{c}}$ & 0.466 & 14.5 \\
2PyDBSMA $^{\text {D2PyMA }}$ & 2.86 & 2520 \\
D2P $^{\mathrm{c}}$ & 0.0165 & 1620
\end{tabular}

${ }^{\mathrm{a}}$ Concentration, $0.39-0.40 \mathrm{moll}^{-1}$. ${ }^{\mathrm{b}}$ Pseudo first-order rate constant. ${ }^{\mathrm{C}}$ Data from ref 18. strate the ester linkage in the polymers of PDBSMA and 2PyDBSMA to be more resistant against methanolysis than that in poly(TrMA) and poly(D2PyMA), respectively.

\section{Asymmetric Anionic Polymerization of PDBSMA}

Anionic polymerization was carried out in toluene at $-78^{\circ} \mathrm{C}$. The reaction was performed in an optical cell in order to monitor change in optical rotation of the reaction system or in a glass ampoule. Figure 2 shows changes in optical rotation during the reaction at a feed ratio of [monomer]/[initiator] of 10 . In all three systems, optical activity increased in a positive direction with reaction time and reached large positive values $\left([\alpha]_{435}^{-78}+1510^{\circ}\right.$ (DDB-system), $+1500^{\circ}$ (PMP-system) and $+1060^{\circ}$ (Sp-system in $\left.12 \mathrm{~h}\right)$ ), suggesting the formation of one-handed helical polymers. Assuming that the optical activity is based mainly on the one-handed helical polymers, the graphs in Figure 2 can be taken as time-conversion plots. The reaction with DDB seems the fastest and that with $\mathrm{Sp}$, the slowest. The results of polymerization of PDBSMA with DDB and PMP are in contrast to that the polymerization of TrMA with DDB- $n$-butyllithium needed $c a .2 \mathrm{~h}^{5}$ to reach maximum rotation while that with PMP-9-fluorenyllithium, only 10 min. $^{6}$

The conditions and results of polymerization in a larger scale using a glass ampoule are summarized in Table II. In all runs, the products were obtained quantitatively. GPC traces of the MeOH-insoluble polymers are shown in Figure 3. The products consisted of optically active polymers and oligomers showing only negligible optical activity (asterisked peaks in the chromatograms). The products from $\mathrm{Sp}$ - and DDB-reaction systems

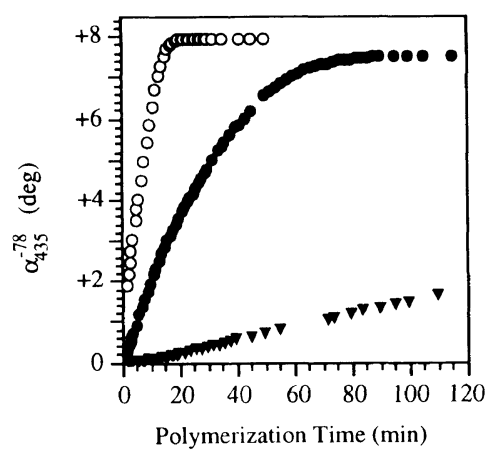

Figure 2. Changes in optical activity of polymerization systems of PDBSMA with DDB $(\bigcirc)$, PMP $(\bullet)$, and $\mathrm{Sp}(\boldsymbol{\nabla})$ in toluene at $-78^{\circ} \mathrm{C}$. Conditions: cell length, $1.0 \mathrm{~cm}$; monomer, $0.15 \mathrm{~g}$; toluene, $3 \mathrm{ml}$; [monomer]/[initiator], 10 .

Table II. Asymmetric anionic polymerization of PDBSMA with DPEDA-Li complexes ${ }^{\mathrm{a}}$

\begin{tabular}{|c|c|c|c|c|c|c|c|c|c|c|c|c|c|}
\hline \multirow{3}{*}{ Run } & \multirow{3}{*}{$\begin{array}{l}\text { Chiral } \\
\text { ligand }\end{array}$} & \multirow{3}{*}{$\begin{array}{c}\text { Time } \\
\mathrm{h}\end{array}$} & \multirow{3}{*}{$\frac{\text { Yield }^{\mathrm{b}}}{\%}$} & \multirow{3}{*}{$\mathrm{DP}^{\mathrm{c}}$} & \multirow{3}{*}{$M_{w} / M_{n}^{\mathrm{c}}$} & \multirow{3}{*}[\alpha]{$_{365}^{25}{ }^{d}$} & \multirow{3}{*}[\alpha]{$_{\mathrm{D}}^{25 \mathrm{~d}}$} & \multicolumn{6}{|c|}{ Benzene-hexane (1/1)-insoluble part ${ }^{\mathrm{e}}$} \\
\hline & & & & & & & & Yield & $\mathrm{DPc}^{2}$ & & Tacticity, $m m^{\mathrm{f}}$ & & \\
\hline & & & & & & & & $\%$ & & $w / x_{n}$ & $\%$ & {$[\sqrt{365}$} & $J \mathrm{D}$ \\
\hline 1 & $\mathrm{Sp}$ & 24 & $>99$ & 47 & 1.76 & $+1220^{\circ}$ & $+310^{\circ}$ & 71 & 80 & 1.30 & $>99$ & $+1670^{\circ}$ & $+422^{\circ}$ \\
\hline 2 & DDB & 3 & $>99$ & 39 & 1.16 & $+1660^{\circ}$ & $+430^{\circ}$ & 86 & 48 & 1.07 & $>99$ & $+1778^{\circ}$ & $+477^{\circ}$ \\
\hline 3 & PMP & 3 & $>99$ & 40 & 1.10 & $+1770^{\circ}$ & $+460^{\circ}$ & 95 & 43 & 1.10 & $>99$ & $+1755^{\circ}$ & $+468^{\circ}$ \\
\hline
\end{tabular}

${ }^{a}$ Conditions: monomer, $1.0 \mathrm{~g}$; toluene, $20 \mathrm{ml}$; temperature, $-78^{\circ} \mathrm{C}$; [monomer]/[Li], 20. ${ }^{\mathrm{b}} \mathrm{MeOH}$-insoluble part. ${ }^{\mathrm{c}}$ Determined by $\mathrm{GPC}$ of poly(MMA) derived from poly(PDBSMA). ${ }^{\mathrm{d}}$ Measured in tetrahydrofuran (conc. $0.5 \mathrm{~g} \mathrm{dl}^{-1}$ ). ${ }^{\mathrm{e}}$ Data from ref $12 .{ }^{\mathrm{f}}$ Determined from ${ }^{1} \mathrm{H}$ NMR sepctra of poly(MMA) derived from poly(PDBSMA). ${ }^{\mathrm{g}}$ Measured in tetrahydrofuran (conc. $1.0 \mathrm{~g} \mathrm{dl}^{-1}$ ). 
(A)

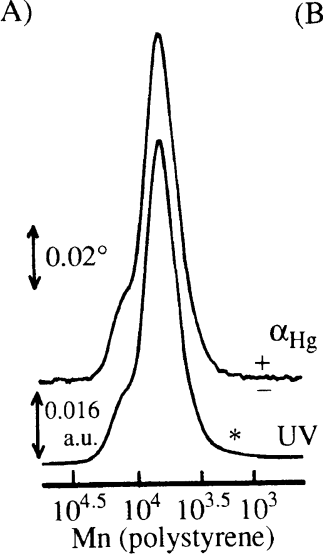

(B)

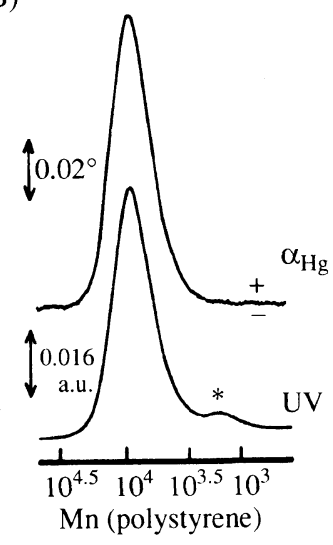

(C)

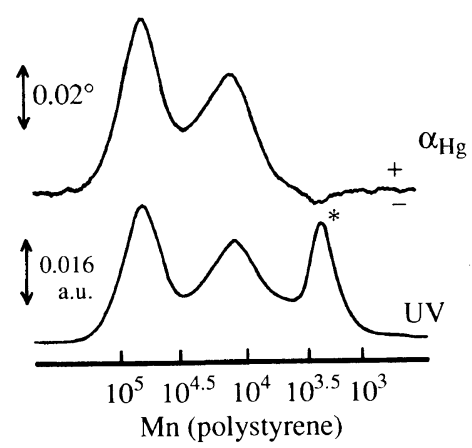

Figure 3. GPC curves of $\mathrm{MeOH}$-insoluble poly(PDBSMA)s prepared with PMP (A), DDB (B), and Sp (C). For each of (A)-(C), the top curve shows the response of the polarimetric $\left(\alpha_{\mathrm{Hg}}\right)$ detector and the bottom one, that of the UV $(254 \mathrm{~nm})$ detector. Asterisked peaks are based on oligomers.

contained higher amount of oligomers than that from PMP-system. The production of oligomers in addition to the optically active polymer has been found also for the polymerization systems of TrMA. ${ }^{6}$ This can be explained in terms of different activities of propagating species giving the polymer and the oligomers. The activity depends on the absolute configuration of mainchain chiral centers. ${ }^{6}$ The production of oligomers in the present study may be interpreted in the same manner. The oligomers could be removed by fractionation with a benzene-hexane mixture $(1: 1, \mathrm{v} / \mathrm{v}){ }^{6}$ The oligomerfree polymers were almost perfectly isotactic and showed large dextrorotation. The values of rotation were larger than those of one-handed helical poly(TrMA) and, as can be seen in Figure 3, the UV chromatograms of GPC well corresponded to the polarimetric chromatograms except for the oligomer region. HPLC resolution of the $(+)$-polymer obtained with the PMP complex using (+)- and (-)-poly(TrMA)s chemically bonded to silica gel as stationary phases ${ }^{19}$ did not show the presence of the (-)-fraction. ${ }^{20}$ These results indicate that the optical activity of the polymers is based on the onehanded helical conformation of the polymer chain. The benzene-hexane-insoluble polymer obtained with PMPDPEDA-Li showed strong circular dichroims absorptions (Figure 4). The molecular ellipticity of the CD peaks is comparable to that of one-handed helical poly(TrMA). ${ }^{6}$ The polymers obtained with DDB and PMP complexes had narrow molecular weight distributions even before fractionation with a benzene-hexane mixture. We have already shown that the polymer obtained with the PMP complex exhibits chiral recognition

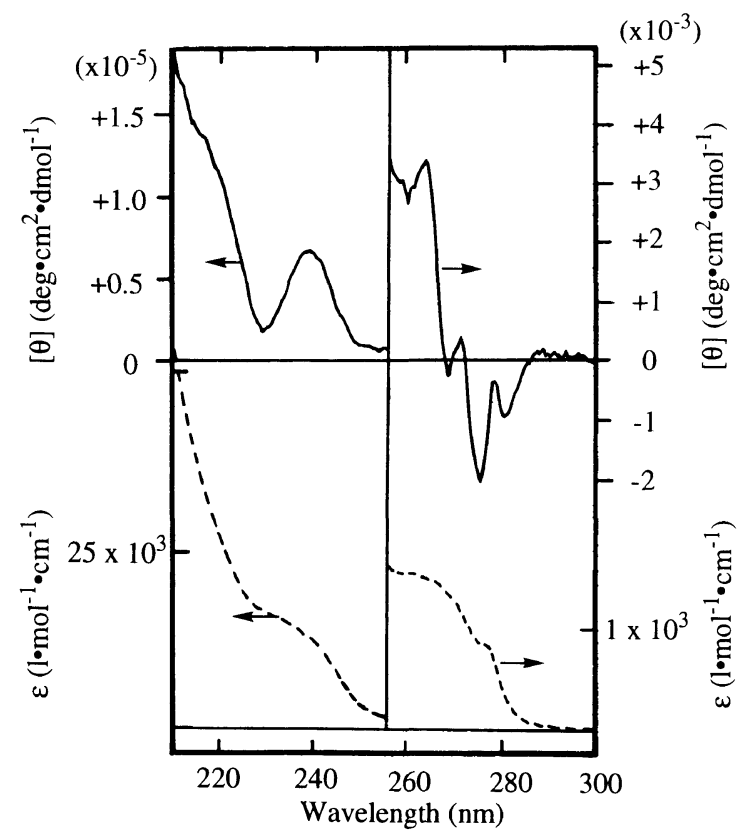

Figure 4. CD (solid curve) and absorption (dotted curve) spectra of the oligomer-free poly(PDBSMA) prepared with PMP-DPEDA-Li (run 3 in Table II). [ $\theta$ ] and $\varepsilon$ were calculated with respect to molar amount of the monomeric residue. The arrows on the curves indicate corresponding ordinates.
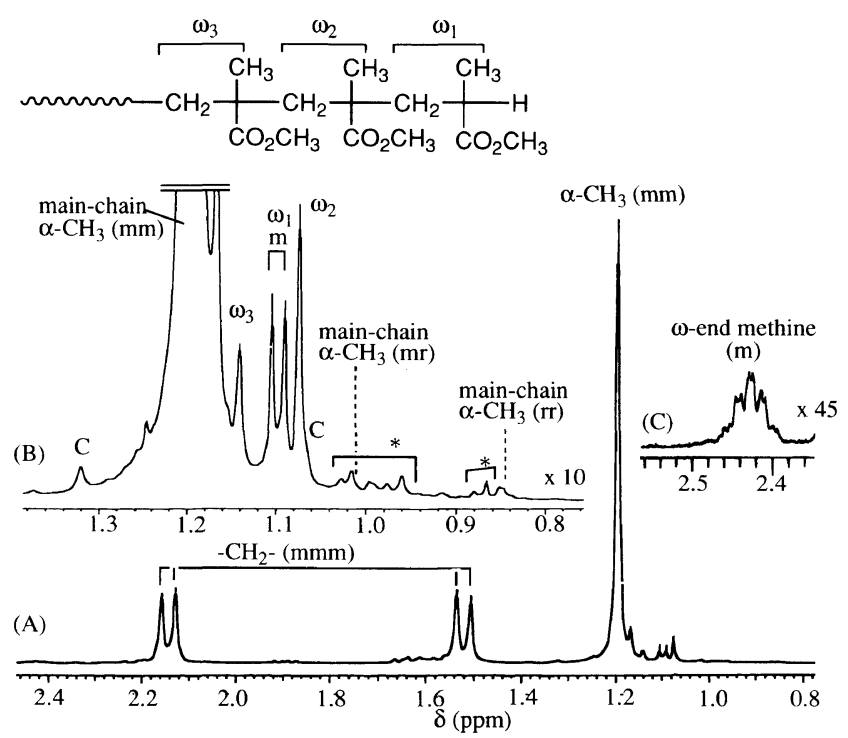

Figure 5. ${ }^{1} \mathrm{H}$ NMR spectra of the PMMA derived from the oligomerfree poly(PDBSMA) prepared with PMP-DPEDA-Li (run 3 in Table II). $\mathrm{C}$ and ${ }^{*}$ denote ${ }^{13} \mathrm{C}$ satellite bands and unassigned peaks which are probably due to impurities, respectively. The structure of $\omega$-end vicinity of PMMA is shown above (B) with the numbering system of monomeric units.

ability toward some racemic compounds. ${ }^{12}$

It is notable that the GPC curve of the optically active polymer obtained with $\mathrm{Sp}$ complex showed a bimodal molecular weight distribution much broader than 1.30 as determined by GPC of poly(MMA) derived from the original polymer. The higher-molecular-weight peak in the GPC curve appears to be ascribable to aggregated polymer chain observed for helical poly(diphenyl-2pyridylmethyl methacrylate). ${ }^{11}$

The tacticity of the polymers was determined by ${ }^{1} \mathrm{H}$ NMR analysis of PMMAs derived from the original polymers. The spectra of PMMA derived from the 
Table III. Asymmetric anionic polymerization of 2PyDBSMA with DPEDA-Li complexes ${ }^{\mathrm{a}}$

\begin{tabular}{|c|c|c|c|c|c|c|c|c|c|}
\hline \multirow{3}{*}{ Run } & \multirow{3}{*}{$\begin{array}{l}\text { Chiral } \\
\text { ligand }\end{array}$} & \multirow{3}{*}{$\begin{array}{c}\text { Time } \\
\mathrm{h}\end{array}$} & \multicolumn{3}{|c|}{$\mathrm{MeOH}$-insoluble product } & \multicolumn{4}{|c|}{ Benzene-hexane (1/1)-insoluble part } \\
\hline & & & Yield & & & Yield & & & Tacticity, $\mathrm{mm}^{\mathrm{d}}$ \\
\hline & & & $\%$ & {$[a] 365$} & {$[\mathrm{~L}] \mathrm{D}$} & $\%$ & & $w / / 2 x_{n}$ & $\%$ \\
\hline 1 & $\mathrm{Sp}$ & 97 & 49 & $+1290^{\circ}$ & & 79 & 61 & 1.07 & $>99$ \\
\hline $2^{\mathrm{e}}$ & DDB & 48 & 11 & $+120^{\circ}$ & & & & & \\
\hline 3 & PMP & 48 & 98 & $+1620^{\circ}$ & $+380^{\circ}$ & $>99$ & $50^{\mathrm{f}}$ & 1.07 & $>99$ \\
\hline
\end{tabular}

${ }^{\mathrm{a}}$ Conditions: monomer, $1.0 \mathrm{~g}$ (runs 1 and 2) $2.0 \mathrm{~g}$ (run 3); toluene, $20 \mathrm{ml}$ (runs 1 and 2) $40 \mathrm{ml}$ (run 3); temperature, $-78^{\circ} \mathrm{C}$; [monomer]/[Li], 20. ${ }^{\mathrm{b}}$ Measured in $\mathrm{CHCl}_{3}$ immediately after being dissolved (conc. $0.1 \mathrm{~g} \mathrm{dl}^{-1}$ ). ${ }^{\mathrm{c}}$ Determined by $\mathrm{GPC}$ analysis the poly(MMA)s derived from the poly(2PyDBSMA) using polystyrene standard samples. ${ }^{\mathrm{d}}$ Determined from ${ }^{1} \mathrm{H}$ NMR spectra of poly(MMA) derived from poly(2PyDBSMA). ${ }^{\text {e }}$ The product of this run was not fractionated with a benzene-hexane mixture. DP and $M_{w} / M_{n}$ of the MeOH-insoluble polymer were determined to be 15 and 1.05, respectively, from the GPC curve of the original poly(2PyDBSMA) using a coefficient of 2.6 shown in footnote f. The poly(MMA) derived from the methanol-insoluble polymer was highly isotactic $(m m>99)$. ${ }^{\mathrm{f}} \mathrm{DP}$ and $M_{\mathrm{w}} / M_{n}$ were determined to be 19 ( $v s$. standard polystyrenes) and 1.18, respectively, on the basis of the GPC curve of the original poly(2PyDBSMA) although these values are not as reliable as those determined by poly(MMA) sample derived from the original polymer. This suggests that DP determined from the GPC of the poly(MMA) and that of the original polymer may be correlated with a coefficient of $2.6(50 / 19)$. (See footnote e).

polymer obtained from PMP-system are shown in Figure 5. Spectrum (A) shows a typical $A B$ quartet splitting of methylene protons based on the $\mathrm{mmm}$ tetrad and expanded spectrum (B) for the $\alpha$-methyl signals does not show clear peaks of $m r$ and $r r$ triads. These results mean that the main chain of this polymer has an almost perfectly isotactic configuration. The highly isotactic structure was evident also for the $\omega$-end of the chain. The signals marked as $\omega_{n}$ are based on the $\alpha$-methyl groups in the vicinity of the $\omega$-end of the polymer chain (see the structure shown in Figure 5); the assignments are based on the previous reports. ${ }^{6,21}$ It is known that the $\omega$-end methyl signals (doublet) based on meso $\omega$-end configuration appear in a higher magnetic field than those based on racemo $\omega$-end configuration. ${ }^{22,23}$ In spectrum (B), only the meso-based doublet peaks (around $1.1 \mathrm{ppm}$, marked as $\left.\omega_{1}\right)$ are seen, indicating that protonation (termination) of the growing anion took place exclusively in meso fashion. The $\omega$-end meso structure can also be confirmed from the $\omega$-end methine signals (spectrum (C)).

\section{Asymmetric Anionic Polymerization of 2PyDBSMA}

2PyDBSMA also gave optically active, highly isotactic polymers by asymmetric anionic polymerization (Table III, Figure 6) where only the polymerization with PMP-DPEDA-Li gave a quantitative yield. Figure 6 shows changes in optical activity of the polymerization systems in an optical cell. From the graphs, the polymerization with PMP-DPEDA-Li seems much faster than the others; however, even this polymerization is slower than the polymerization of PDBSMA described above and also than that of D2PyMA under the same reaction conditions. Monitoring of optical activity of the PMP-system was disturbed in ca. $500 \mathrm{~min}$ after initiation reaction because the reaction system became cloudy, suggesting that the product precipitated out. The other polymerization systems remained clear throughout the reaction. The rotation of the $\mathrm{Sp}$-system initially became negative and then turned positive similarly to the polymerization of TrMA with $\mathrm{Sp}-\mathrm{BuLi}$ in toluene at $-78^{\circ} \mathrm{C}$ (Figure $6(\mathrm{~B}))^{4}$

The isolated polymer from the reaction on a larger scale with PMP-DPEDA-Li showed specific rotation
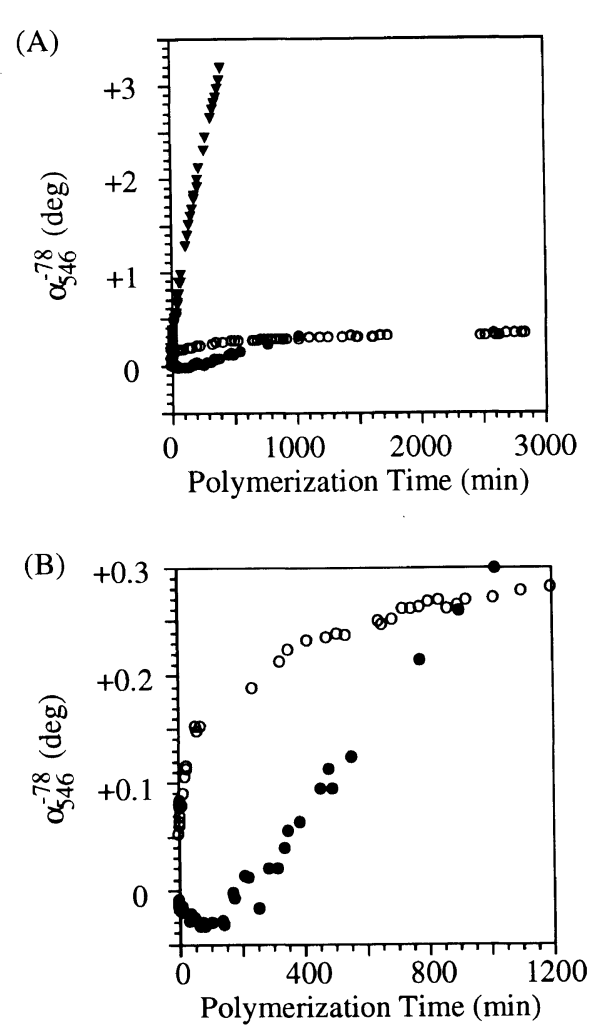

Figure 6. Changes in optical activity of polymerization systems of 2PyDBSMA with DDB $(O)$, PMP $(\boldsymbol{\nabla})$, and Sp $(\bullet)$ in toluene at $-78^{\circ} \mathrm{C}$. Conditions: cell length, $1.0 \mathrm{~cm}$; monomer, $0.15 \mathrm{~g}$; toluene, $3 \mathrm{ml}$; [monomer]/[initiator], 20.

comparable to those of one-handed helical poly(PDBSMA) (run 3 in Table III) and also, the GPC curve obtained with a polarimetric detector corresponded well to that obtained with a UV detector (Figure 7 (A)), suggesting that this poly(2PyDBSMA) has a one-handed helical conformation. The product of run 3 in Table III contained only small amounts of oligomers and the polymer had a narrow molecular weight distribution, suggesting this reaction system has a living nature. This polymer showed $\mathrm{CD}$ absorptions (Figure 8) whose intensities were comparable to those of one-handed helical poly(TrMA) and poly(D2PyMA).

The optical rotation of the polymer obtained with 
(A)

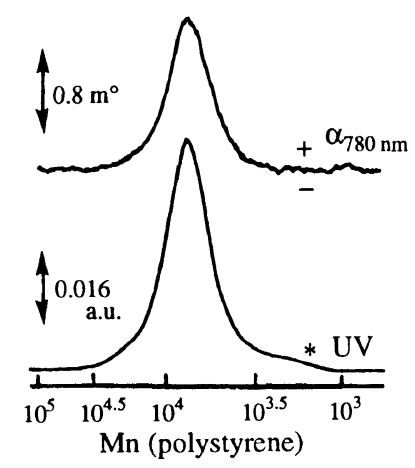

(B)

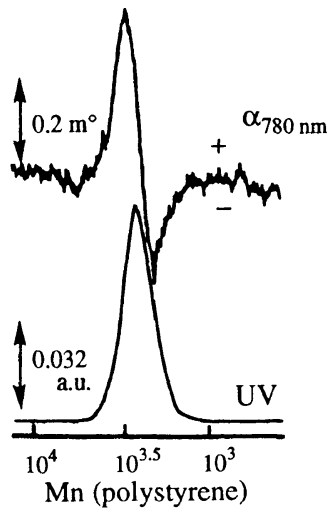

(C)

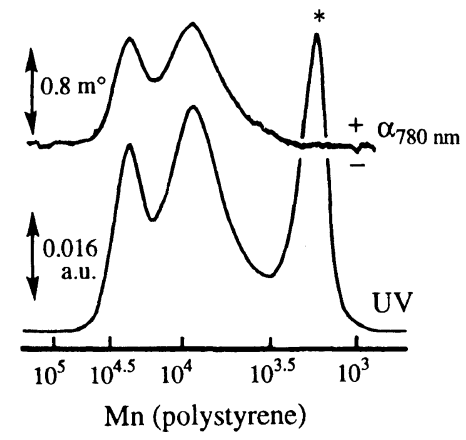

Figure 7. GPC curves of MeOH-insoluble poly(2PyDBSMA)s prepared with PMP (A), DDB (B), and Sp (C). For each of (A)-(C), the top curve shows the response of the polarimetric $\left(\alpha_{780 \mathrm{~nm}}\right)$ detector and the bottom one, that of UV $(254 \mathrm{~nm})$ detector. Asterisked peaks are based on oligomers.

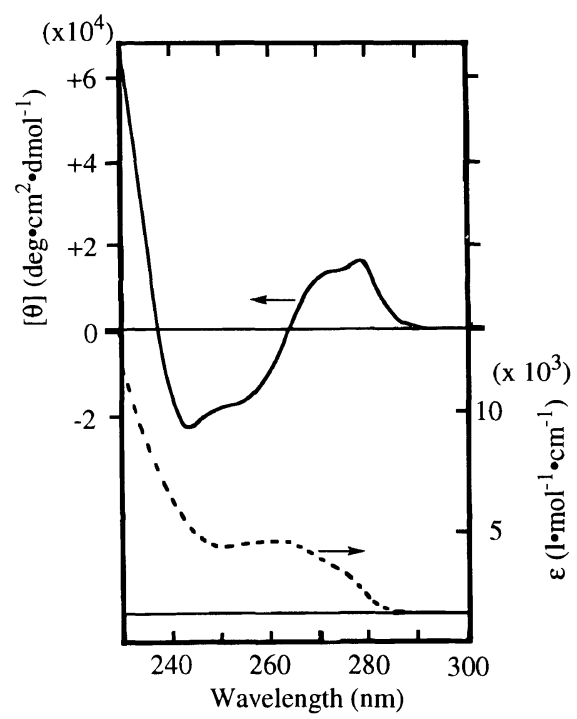

Figure 8. $\mathrm{CD}$ (solid curve) and absorption (dotted curve) spectra of the oligomer-free poly(2PyDBSMA) prepared with PMP-DPEDA-Li (run 3 in Table III). [ $\theta]$ and $\varepsilon$ values were calculated with respect to molar amount of the monomeric residue.

Sp-DPEDA-Li was smaller than that of the polymer from the PMP-system. This is because the MeOHinsoluble polymer contains a significant amount of oligomers (Figure 7 (C)). Though the oligomers were removed by fractionating the polymer with a benzenehexane mixture, optical rotation measurement of the oligomer-free polymers was difficult because the polymer showed lower solubility in $\mathrm{CHCl}_{3}$ and THF after removal of oligomers. However, the specific rotation of the oligomer-free poly(2PyDBSMA) obtained with
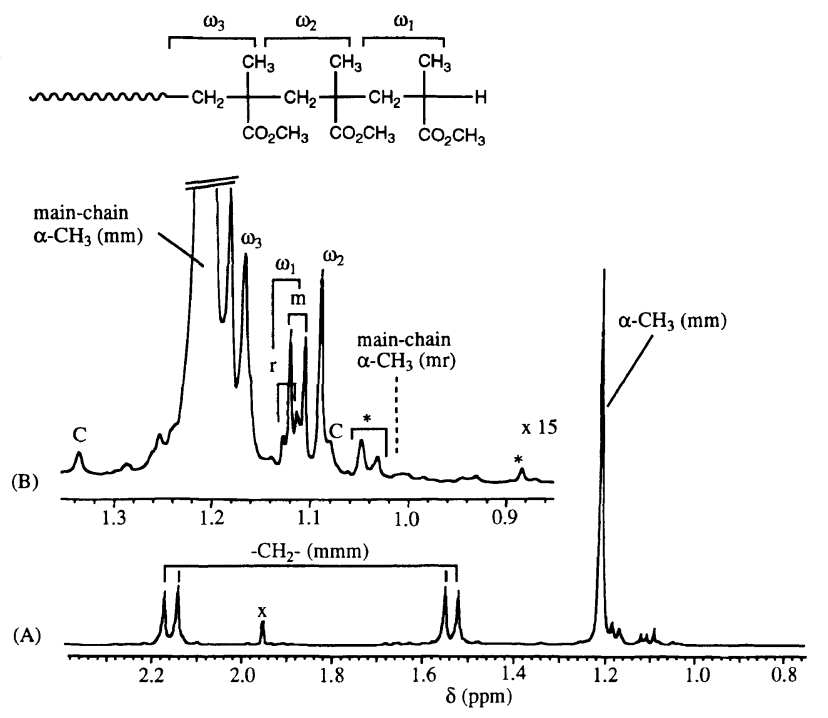

Figure 9. ${ }^{1} \mathrm{H}$ NMR spectra of PMMA derived from the poly(2PyDBSMA) prepared with PMP-DPEDA-Li (run 3 in Table III). $\mathrm{C}$ and ${ }^{*}$ denote ${ }^{13} \mathrm{C}$ satellite bands and unassigned peaks probably due to impurities, respectively. The structure of $\omega$-end vicinity of PMMA is shown above (B) with the numbering system of monomeric units.

Sp-DPEDA-Li was estimated as $[\alpha]_{365}+1630^{\circ}$ using the content of oligomers $(21 \%)$ and specific rotation of the sample containing the oligomers $\left([\alpha]_{365}+1290^{\circ}\right)$, suggesting that this polymer has one-handed helical conformation. This is interesting since the polymerization of D2PyMA with $\mathrm{Sp}$ ligand gave a mixture of right- and left-handed helices and the low helix-sense selectivity has been ascribed to coordination of the 2-pyridyl group to the Li cation at the growing end which prevents the coordination of $\mathrm{Sp}$ to the $\mathrm{Li}$ cation. ${ }^{10,11 \mathrm{a}}$ Rigidity and bulkiness of dibenzosuberyl structure may prevent coordination of the 2-pyridyl group to Li cation.

The polymer obtained with DDB-DPEDA-Li showing the smallest specific rotation among the three poly(2PyDBSMA)s consisted of the $(+)$-fraction of higher molecular weight and $(-)$-fraction of lower molecular weight as seen from the GPC curve (Figure 8 (B)), indicating that there are at least two propagating species giving the $(+)$ - and $(-)$-fractions.

Figure 9 shows the ${ }^{1} \mathrm{H}$ NMR spectra of the PMMA derived from the polymer synthesized with PMP DPEDA-Li. A highly isotactic structure was evident from the spectra similarly to the case of the poly(PDBSMA). However, the protonation (termination) stereochemistry appears less selective in 2PyDBSMA polymerization than in PDBSMA polymerization from the signals based on the $\omega$-end methyl group. The $\omega$-end $m / r$ ratio was $c a .8 / 2$.

\section{Chiral Recognition Ability of Optically Active Poly- (2PyDBSMA)}

Optically active poly(2PyDBSMA) exhibited chiral recognition of several compounds when adsorbed on macroporous silica gel and used as a stationary phase of HPLC. The results of HPLC resolution by the poly(2PyDBSMA) are shown in Table IV with those by optically active (-)-poly(D2PyMA). The resolution ability of poly(2PyDBSMA) appeared less than that of 
Table IV. Resolution of racemates by HPLC using $(+)-\operatorname{poly}(2 \mathrm{PyDBSMA})$ as a stationary phase $^{\mathrm{a}}$

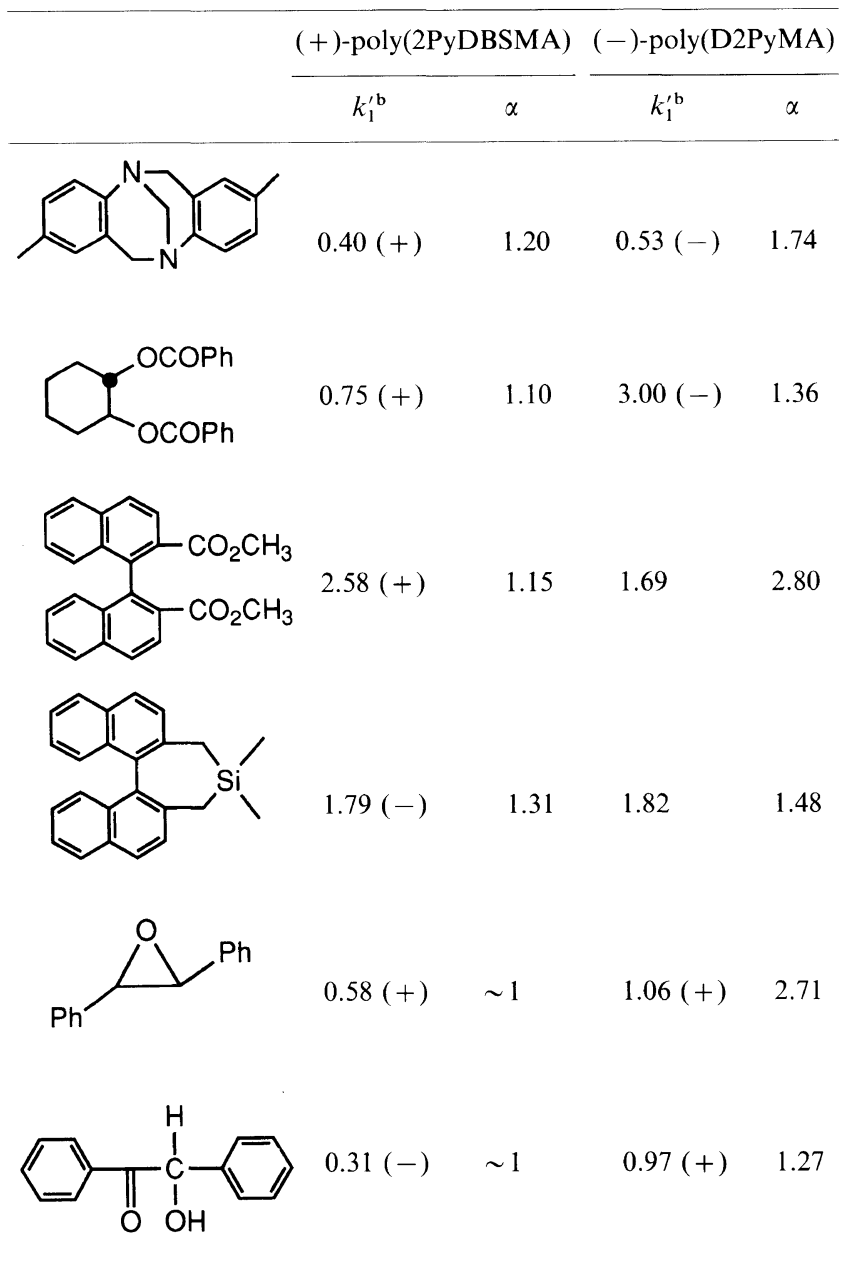

${ }^{\mathrm{a}} k_{1}^{\prime}=\left(t_{1}-t_{0}\right) / t_{0}, k_{2}^{\prime}=\left(t_{2}-t_{0}\right) / t_{0}$, and $\alpha=k_{2}^{\prime} / k_{1}^{\prime}$ where $t_{1}$ and $t_{2}$ are elution volumes of the antipodes of a racemate and $t_{0}$ is the dead volume of the HPLC column. The data for (-)-poly(D2PyMA) are cited from ref $18 .{ }^{\mathrm{b}}$ Sign of rotation of the first-eluted antipode is shown in parenthesis.

poly(D2PyMA). ${ }^{18}$ This may be because the ester group of the poly(2PyDBSMA) cannot take a propeller structure, which is considered important in chiral recognition by poly(D2PyMA) and poly(TrMA), since the two phenyl groups are tied to each other. Alternatively, the ethylene group may prevent the effective enantioselective adsorption.

\section{Summary}

The asymmetric anionic polymerization of two novel monomers was studied. PDBSMA and 2PyDBSMA showed higher resistance against methanolysis than TrMA and D2PyMA, respectively. PDBSMA gave highly isotactic, one-handed polymers by polymerization with $\mathrm{Sp}-$, DDB-, and PMP-DPEDA-Li while 2PyDBSMA did by polymerization with $\mathrm{Sp}-$ and PMP-DPEDA-Li but not with DDB-DPEDA-Li. Poly(PDBSMA) obtained using the PMP ligand had a perfectly isotactic configuration including the $\omega$-end. The optically active poly(2PyDBSMA) exhibited chiral recognition of several racemic compounds to a lesser extent than that of poly(D2PyMA).

Acknowledgments. The authors thank Mr. Y. Shikisai for experimental assistance. This work was supported, in part, by the Grant-in-Aid for Scientific Research on Priority Area of Reactive Organometallics (No. 05236103) from the Ministry of Education, Science, and Culture of Japan.

\section{REFERENCES}

1. The IUPAC systematic name for 1-phenyldibenzosuberyl methacrylate is 5-phenyl-10,11-dihydrodibenzo[ $a, d]$ cyclohepten-5-yl methacrylate and an alternative trivial name is 5-phenyldibenzosuberan-5-yl methacrylate. The IUPAC systematic name for 1 -(2-pyridyl)phenyldibenzosuberyl methacrylate is 5-(2-pyridyl)-10,11-dihydrodibenzo[ $a, d]$ cyclohepten-5-yl methacrylate and an alternative trivial name is 5-(2-pyridyl)dibenzosuberan5-yl methacrylate.

2. Y. Okamoto and T. Nakano, Chem. Rev., 94, 349 (1994).

3. Y. Okamoto, K. Suzuki, K. Ohta, K. Hatada, and H. Yuki, J. Am. Chem. Soc., 101, 4763 (1979).

4. Y. Okamoto, K. Suzuki, and H. Yuki, J. Polym. Sci., Polym. Chem. Ed., 18, 3043 (1980).

5. Y. Okamoto, H. Shohi, and H. Yuki, J. Polym. Sci., Polym. Lett. Ed., 21, 601 (1983).

6. T. Nakano, Y. Okamoto, and K. Hatada, J. Am. Chem. Soc., 114, 1318 (1992).

7. Y. Okamoto, CHEMTECH, 144 (1987).

8. Y. Okamoto, E. Yashima, M. Ishikura, and K. Hatada, Polym. J., 19, 1183 (1987).

9. C. Ren, C. Chen, F. Xi, T. Nakano, and Y. Okamoto, J. Polym. Sci., A, Polym. Chem., 31, 2721 (1993).

10. Y. Okamoto, M. Ishikura, K. Hatada, and H. Yuki, Polym. J., 15, 851 (1983).

11. a) Y. Okamoto, H. Mohri, T. Nakano, and K. Hatada, Chirality, 3, 277 (1991); b) Y. Okamoto, H. Mohri, and K. Hatada, Chem. Lett., 1879 (1988).

12. Y. Okamoto, T. Nakano, Y. Shikisai, and M. Mori, Macromol. Symp., 89, 479 (1995).

13. a) T. Nakano, M. Mori, and Y. Okamoto, Macromolecules, 26, 867 (1993); b) T. Nakano, Y. Shikisai, and Y. Okamoto, Polym. $J ., 28,51$ (1996); c) T. Nakano, A. Matsuda, and Y. Okamoto, to be published.

14. We reported the mp of PDBSMA to be $116-117^{\circ} \mathrm{C}$. However, we obtained an $\mathrm{mp}$ of $157-158^{\circ} \mathrm{C}$ for the same monomer prepared by an independent experiment, suggesting the polymorphism for the monomer crystal.

15. The IUPAC systematic name for 1-(2-pyridyl)dibenzosuberol is 5-(2-pyridyl)-10,11-dihydrodibenzo[a,d]cyclohepten-5-ol and an alternative trivial name is 5-(2-pyridyl)dibenzosuberan-5-ol.

16. S. O. Winthrop, M. A. Davis, G. S. Myers, J. G. Gavin, R. Thomas, and R. Barber, J. Org. Chem., 27, 230 (1962).

17. The correlation in Figure 1(B) might not be linear.

18. Y. Okamoto, H. Mohri, and K. Hatada, Polym. J., 21, 439 (1989).

19. Y. Okamoto, H. Mohri, M. Nakamura, and K. Hatada, Nippon Kagaku Kaishi (Japan), 435 (1987). [Chem. Abstr., 106, 14808a (1987)]

20. The optically active poly(TrMA) chemically bonded to silica gel ${ }^{19}$ can resolve highly isotactic poly(PDBSMA) obtained by radical polymerization under achiral conditions, which is an equimolar mixture of right- and left-handed helices. The details of radical polymerization were published elsewhere ${ }^{13 \mathrm{~b}}$.

21. K. Ute, T. Nishimura, and K. Hatada, Polym. J., 21, 1027 (1989).

22. T. Nakano, Y. Okamoto, and K. Hatada, Polym. J., 27, 882 (1995).

23. K. Ute, T. Asada, N. Miyatake, and K. Hatada, Makromol. Chem., Macromol. Symp., 67, 147 (1993). 